\title{
EMPREENDIMENTOS IMOBILIÁRIOS E A NATUREZA MITIFICADA: O CASO DO CONDOMÍNIO BOULEVARD DAS COLINAS NA CIDADE DE CAETITÉ - BA
}

\author{
Real estate developments and the mitified nature: the case of the Boulevard das Colinas \\ condominium in the city of Caetité - BA
}

\section{Los desarrollos inmobiliarios y la naturaleza mitificada: el caso del condominio Boulevard das Colinas em la ciudad de Caetité - BA}

Roberval Soares Santos ${ }^{1}$ https://orcid.org/0000-0002-1411-4848

Mário Rubem Costa Santana ${ }^{2}$ https://orcid.org/0000-0001-6027-8707

\footnotetext{
${ }^{1}$ Mestre em Geografia pela Universidade Estadual do Sudoeste da Bahia, email - ruberss@ yahoo.com.br

${ }^{2}$ Professor Titular B do Departamento de Geografia e do Programa de Pós-Graduação (PPGEo) da Universidade da Universidade Estadual do Sudoeste da Bahia - UESB, email - mariorubem@gmail.com
}

Recebido em: 20/03/2019

Aceito para publicação em: 11/05/2019

\begin{abstract}
Resumo
Este artigo engendra uma discussão acerca dos empreendimentos imobiliários, neste caso, os espaços residenciais fechados e a natureza mitificada produzida sobre uma estrutura ideológica. Os espaços residenciais fechados promovem a criação de ambientes urbanos, fictícios de retorno a natureza, sintetizam e simplificam a realidade da cidade e promovem a fragmentação socioespacial. Buscou-se entender teorias e conceitos construídos ao longo da historia sobre a natureza e a cidade. E no caso concreto analisar o condomínio Boulevard das Colinas na Cidade de Caetité - BA, onde os incorporadores imobiliários apropriam do discurso ideológico do "natural", através de propagandas, que têm como objetivo a valorização do empreendimento. Observa-se, que através das propagandas muitas ideias de afastamento, diferenciação começam a se materializar no espaço urbano.
\end{abstract}

Palavras-Chave: Espaços fechados. Natureza mitificada. Boulevard das Colinas.

\begin{abstract}
This article engenders a discussion about real estate developments, in this case, the closed residential spaces and the mythical nature produced on an ideological structure. The closed residential spaces promote the creation of urban environments, fictitious of return to nature, synthesize and simplify the reality of the city and promote the socio-spatial fragmentation. We sought to understand theories and concepts constructed throughout history about nature and the city. And in the concrete case analyze the condominium Boulevard das Colinas in the City of Caetité - BA, where the real estate developers appropriate the ideological discourse of the "natural", through advertisements, which have the
\end{abstract}


purpose of valuing the enterprise. It is observed that through the advertisements many ideas of distance, differentiation begin to materialize in the urban space.

Keywords: Closed space. Mitified nature. Boulevard das Colinas.

\section{Resumen}

Este artículo engendra una discusión sobre los emprendimientos inmobiliarios, en este caso, los espacios residenciales cerrados y la naturaleza mitificada producida sobre una estructura ideológica. Los espacios residenciales cerrados promueven la creación de ambientes urbanos, ficticios de retorno a la naturaleza, sintetizan y simplifican la realidad de la ciudad y promueven la fragmentación socioespacial. Se buscó entender teorías y conceptos construidos a lo largo de la historia sobre la naturaleza y la ciudad. Y en el caso concreto analizar el condominio Boulevard das Colinas en la Ciudad de Caetité - BA, donde los incorporadores inmobiliarios apropia del discurso ideológico del "natural", a través de propagandas, que tienen como objetivo la valorización del emprendimiento. Se observa, que a través de las propagandas muchas ideas de alejamiento, diferenciación empiezan a materializarse en el espacio urbano.

Palabras clave: Espacios cerrados. Naturaleza mitificada. Boulevard de las colinas.

\section{Introdução}

Como um processo dinâmico que permeia e se materializa no espaço, os loteamentos fechados são configurações espaciais decorrentes da produção do espaço urbano que modificam as cidades direcionadas espacialmente pelos capitais imobiliários. Partindo dessa premissa, este trabalho tem por finalidade produzir um enfoque reflexivo e analítico sobre a utilização e propagação da ideia de retorno à natureza incorporada pelos empreendimentos imobiliários, sob a égide de uma estrutura ideológica pautada em uma conduta préestabelecida para obtenção de lucros através do discurso do natural.

Então, ao se falar de produção e reprodução do espaço, este deve estar conjugado com a produção da natureza, pois como ratifica Smith (1988, p. 109) "a menos que o espaço seja conceituado como realidade completamente separada da natureza, a produção do espaço é um resultado lógico da produção da natureza". Natureza esta, concebida como espaço geográfico que no capitalismo, passa a ser transformada em mercadoria pela valorização do espaço onde o valor de uso é absorvido pelo valor de troca.

Nessa perspectiva, esse trabalho direciona a discussão para a compreensão da materialidade do espaço geográfico alicerçado na relação cidade - natureza com base na construção analítica pautada na apropriação dessa relação pelos empreendimentos 
imobiliários capitalistas, através do discurso ideológico do retorno a natureza (física, sofisticada, embelezada).

Parte-se do pressuposto, aqui, de que a cidade produz múltiplos espaços segregados que revelam ações oriundas da reprodução do capital e da reprodução social e, também, dos conflitos entre as classes sociais, que são a mola propulsora do sistema em vigor. É, portanto, uma reflexão acerca dos processos de valorização e incorporação do espaço, em que se manifestam na estratificação socioespacial embasada na segregação e autosegregação espacial.

O capital imobiliário produz áreas valorizadas para serem consumidas pelas camadas sociais privilegiadas quanto à renda, apropriando na contemporaneidade do discurso do "natural", da "segurança". Produzem também outros espaços menos qualitativos da cidade que comportam as camadas sociais com poder de consumo restrito. Então, os espaços fechados caracterizam-se como formas consolidadas do processo de segregação socioespacial, pois, a lógica capitalista molda e organiza o espaço em função da reprodução e acumulação do capital.

Destarte, essa espacialidade do capital, materializado na produção de uma natureza mitificada pelos empreendimentos imobiliários fechados é estruturada e articulada mediante, a relação sociedade-natureza, que dinamiza, interage, usa e transforma o espaço. Sendo assim, materializa-se a indiferença dos sujeitos e a negação do outro, por meio de espaços que recusam a participação coletiva.

\section{A incorporação da natureza pelos empreendimentos imobiliários}

Com o processo de industrialização, os avanços das técnicas e do capital a incorporação da natureza à vida humana se intensfica. Neste caso, essa incorporação naturezasociedade instiga-nos a repensar cada vez mais os conceitos, conteúdos e limites que esse termo carrega. Neste sentido, Lenoble (1969, apud HENRIQUE, 2009, p. 13) nos seus escritos afirma que "o conceito de natureza esteve empregado para definir e designar ações, objetos e processos". Para o autor definições apressadas do conceito de Natureza podem esconder armadilhas epistemológicas, tanto quanto a proliferação do conceito de Natureza relacionado ao físico-natural.

Desta forma, um caminho para entender o conceito de Natureza não como concepção fechada, mas como possibilidades a respostas que preencham ideias, é entendê-la enquanto 
unidade dialética. Nesse sentido, Silva (2001) salienta que tudo criado pela natureza exterior ou interior ao homem, e por esse produzido, é natureza.

Nessa perspectiva, a natureza enquanto conceito seria uma expressão incorporada à vida social, ao longo da historia humana e apropriada pela produção capitalista como objeto em que se agrega valor de troca. Para Smith (1988) a produção da natureza pelo homem a partir do avanço técnico e da acumulação do capital criaram reais possibilidades para produção da natureza.

Assim, a relação homem e a natureza segundo Marx (1980) é dada pelo trabalho, que é o conjunto histórico de meios instrumentais e sociais, através dos quais os homens realizam a vida. As coisas que no princípio eram dádivas da natureza, com o trabalho e a intenção social, passam a ser objetos.

Desta forma, os sistemas de objetos não mais as coisas, carregam duas dimensões, concreta e simbólica, que incorpora-se à esfera do mundo capitalista e a uma racionalidade instrumental e criam necessidades individuais. Para Marx

No mundo alienado do capitalismo as necessidades não são manifestações de poderes latentes do homem, isto é, elas não são necessidades humanas; no capitalismo, cada homem especula sobre como criar uma nova necessidade em outro homem a fim de forçá-lo a um novo sacrifício, colocá-lo em uma nova dependência, e incitá-lo a um novo tipo de prazer e, por conseguinte, à ruína econômica (MARX, 1962, p. 60-61).

Neste contexto, todas as relações sociedade-natureza, são relações que se reproduzem no espaço. Caberá à Geografia, centrar suas preocupações no "espaço produzido" em que o social-natureza e a natureza-social se entrelaçam. Segundo Smith (1988), existiram suposições que tratavam de forma semelhante os conceitos de natureza e espaço, assim o conceito de espaço esteve por longos anos dado como algo indiscutível e seu significado como algo não problemático.

Nessa perspectiva, só existe o espaço geográfico na relação sociedade-natureza, ao transformar a natureza através da produção capitalista o homem também transforma suas condições de vida. A tendência universalizante, homogeneizante e fragmentadora do capital, pressupõe a exigência da organização com base material 'espaço geográfico' de modo a produzir as condições de fluidez e aceleração da circulação das mercadorias. Para Silva,

O espaço geográfico é produzido pelas relações contraditórias entre a natureza orgânica e inorgânica interior e exterior ao homem. O homem é espaço, está no espaço e produz espaço a um só tempo. Espaço Social. Isto

GEOPAUTA, V. 3 no 1, 2019 http://periodicos2.uesb.br/index.php/geo 
se dá por meio de sua propriedade, pela função, e pelo resultado dessa propriedade (SILVA, 2001, p. 50)

Esse espaço vem se desenvolvendo em uma estrutura socioespacial dinâmica, particularmente após o processo de industrialização. Essa ação intensificou a acumulação de capitais e alterou o conteúdo urbano. As cidades passaram a serem conformadas para atenderem a lógica, produção, mercadoria e consumo, e isto, implicou na desestruturação das estruturas estabelecidas.

Para Lefebvre (1969) as cidades eram antes da industrialização centros de vida social e política, onde se acumulavam não apenas riquezas como também conhecimentos, técnica e obras. A própria cidade era entendida enquanto obra. Nessa perspectiva, a cidade oferecia a boa parte de seus citadinos objetos direcionada ao "uso", existindo uma relação mais solidária entre a cidade e a natureza. Essa relação era representada através das Festas que consumiam “improdutivamente", e sem nenhuma vantagem acumulativa, a natureza produzida.

Desta forma, para compreendermos a relação cidade-natureza e as alterações ocorridas a partir da industrialização, faz-se necessário, uma análise com base em periodização. Neste caso, a periodização é uma possibilidade para o recorte metodológico do tempo, uma possível quebra temporal em períodos sem perder determinadas relações com a totalidade. Partimos, então, da proposta de periodização do fenômeno, defendida por Henrique (2009), em que para o autor existiram cinco períodos onde as ideias e os conceitos de natureza estiveram relacionados à cidade.

Considera-se, assim, que deve-se levar em conta os elementos pertencentes ao sistema temporal e não apenas às datas históricas para que efetivamente tenha a noção de totalidade. Nesse caso, Henrique (2009) descreve que primeiro período é marcado pelo conhecimento sobre a Natureza, construído através da imaginação e contemplação, desenvolvia através dos relatos heroicos dos "desbravadores". A ideia de natureza estava relacionada ao mito. Quanto às cidades estas eram rudimentares, tendo como principais expoentes as cidades gregas. As ações do homem sobre a natureza são dada principalmente pelas técnicas de irrigação, que permitiram o desenvolvimento da agricultura e propiciaram aos homens a produção de alimentos.

Para Henrique (2009), o segundo período é definido pela interpretação da bíblia onde o conhecimento da natureza tem um forte componente teológico. No campo das técnicas, destaca-se a utilização do arado junto à irrigação, este artifício propiciou o aumento agrícola no período. Deve-se ressaltar que mesmo com este aparente desenvolvimento tecnológico o

GEOPAUTA, V. 3 no 1, 2019 http://periodicos2.uesb.br/index.php/geo

Este é um artigo de acesso aberto sob a licença Creative Commons da CC BY 
temor a Deus irá prevalecer sobre a as transformações da natureza, as transformações serão dotadas de valor divino. As cidades terão como características as muralhas, separadas fisicamente da natureza, dos bosques e das florestas, neste contexto, os maiores expoentes são as cidades feudais.

Já o terceiro período é marcado pelas viagens marítimas e comerciais, pelo descobrimento de novas terras e consequentemente o desenvolvimento de novas técnicas que propiciaram a compreensão/representação da natureza. $\mathrm{O}$ incremento das técnicas de transportes, como as caravelas e o balão, expandiram as ações humanas para além das muralhas medievais. As cidades passaram a desenvolver principalmente aquelas que desempenhavam funções comerciais com outros lugares. As ações humanas estavam concentradas em sua maioria nas ciências naturais (física, astronomia, biologia, entre outras), tendo como experimento a dissecação da natureza, na divisão de suas partes (HENRIQUE, 2009).

O quarto período é representado pela mudança na relação do homem com a natureza, marcado pela incorporação da cultura industrial. Os sujeitos passam a se deslocar com mais facilidades graças aos automóveis e aviões. Essa dinâmica marca a incorporação da natureza à vida social, tanto em função das técnicas que foram desenvolvidas e aperfeiçoadas quanto a cultura vigente. Para Henrique (2009, p. 33) "A natureza, neste sentido, passa a ser entendida como recurso". As cidades se tornam celeiro da produção industrial e local da reprodução capitalista. A dinâmica de expansão da cidade atrai segmentos sociais com maior poder econômica para locais que preservem ou reconstituem elementos da natureza (HENRIQUE, 2009).

Finalmente o quinto período é caracterizado pela crise capitalista e intelectual, a sociedade urbana se estabelece e as técnicas atingem escala planetária. Os seres humanos se encontram cada vez mais na qualidade de produtores e consumidores da natureza. As cidades passam a concentrar a maior parte da população e a natureza passa a ser produzida e transformada com o intuito mercadológico, intensificando a ganância pelo lucro. Neste caso, a natureza na cidade, torna-se num objeto de apropriação pelo capitalismo, incorporada no discurso ideológico dos agentes imobiliários (HENRIQUE, 2009).

Ainda nessa perspectiva de desvendamento da relação espaço-cidade-natureza, as cidades retratam com clareza a dimensão do conceito de produção do espaço, onde segundo Lefebvre (1969) a cidade é o lugar onde se produz as obras diversas inclusive aquilo que faz o sentido da produção: necessidades e prazeres. Destacando a abordagem lefebvriana, observa-

GEOPAUTA, V. 3 no 1, 2019 http://periodicos2.uesb.br/index.php/geo

Este é um artigo de acesso aberto sob a licença Creative Commons da CC BY 
se na contemporaneidade os diversos empreendimento imobiliários urbanos fechados (condomínios) que apropriam da produção da natureza (físico-natural) com o objetivo da valorização desses empreendimentos. Simulam uma vida tranquila, atrelando uma ideia de segurança, bosque, paisagismo, áreas verdes.

A natureza enquanto espaço geográfico se torna incorporada e produzida na forma de objetos e ideias. É transformada em recurso pela valorização do espaço onde o valor de uso é absorvido pelo valor de troca. Para Carlos (2004) o espaço que carregava um conteúdo social de valor de uso, passa por meio do modo de produção capitalista incorporar o valor de troca, ou seja, se em um primeiro momento ele era necessário para a produção (da vida humana) e de produtos (a partir da instalação de uma indústria) que seriam consumidos na sociedade, agora ele é produzido para ser consumido enquanto mercadoria. Neste caso, o espaço como produto ou produtor advém das relações sociais diversas, relações estas entre mercadorias específicas da sociedade capitalista - mercadoria terra e mercadoria força de trabalho constituindo um complexo de relações socioespaciais.

Assim, a natureza artificial, que caracteriza o espaço geográfico na contemporaneidade é resultado da produção capitalista. Neste sentido, o espaço passa a ser apropriado de maneira privada, individualista, negando o caráter social da sua produção, encontrando-se "feitichizado" e "coisificado" deslocando as características naturais dos lugares para o espaço enquanto mercadoria.

Nessa perspectiva, a natureza produzida pode se tornar uma ficção ou uma "anomalia", sem vínculos com uma identidade geográfica local. A produção espacial encontra-se hoje compromissada com uma felicidade individual. Assim sendo, o espaço produto capitalista carrega uma natureza ideológica que não mostra toda a história de construção social, uma natureza ideologizada que busca apagar as diferenças dos indivíduos, deslocando "sentimento da identidade social" para as relações de consumo onde os objetos se desdobram em satisfação, poder e felicidade. Para Lefebvre (1969) na ideologia da sociedade capitalista:

Cada 'objeto', cada 'bem' se desdobra numa realidade e numa imagem, fazendo, esta, parte essencial do consumo. Consomem-se tantos signos quanto objetos: signos da felicidade, da satisfação, do poder, da riqueza, da ciência, da técnica etc. A produção desses signos se integra na produção global e desempenha um papel integrador fundamental em relação às outras atividades sociais produtivas ou organizadoras. O signo é comprado e vendido; a linguagem torna-se valor de troca (LEFEBVRE, 1969, p. 62).

GEOPAUTA, V. 3 no 1, 2019 http://periodicos2.uesb.br/index.php/geo 
Desta forma, a cidade produz espaços que sirvam de mercadoria, que são fruto da ação humana e carregam uma densa forma de ideologia onde a presença da natureza natural está muito afastada do social. Neste sentido, o capitalismo como forma de consumo produz um sistema de ideias e símbolos que trazem a presença da natureza natural para a cidade. Além disso, a natureza objeto, efetivamente incorporada e produzida, enclausurada nas propriedades imobiliárias privadas, terá seu acesso definido de forma desigual.

Com processo intenso de urbanização acontece o rompimento do sistema urbano que tinha na cidade o valor de uso. Para Lefebvre (1969) a cidade enquanto obra apresenta seu valor de uso, nas ruas, praças, edifícios e monumentos, as festas que consomem improdutivamente, sem nenhuma outra vantagem, além do prazer e do prestígio. Para Lefebvre (1969, p. 6) "o valor de troca e a generalização da mercadoria pela industrialização tendem a destruir, ao subordiná-las a si, a cidade e a realidade urbana".

Imagem 1 - Infográfico Tridimensional do Boulevard das Colinas.

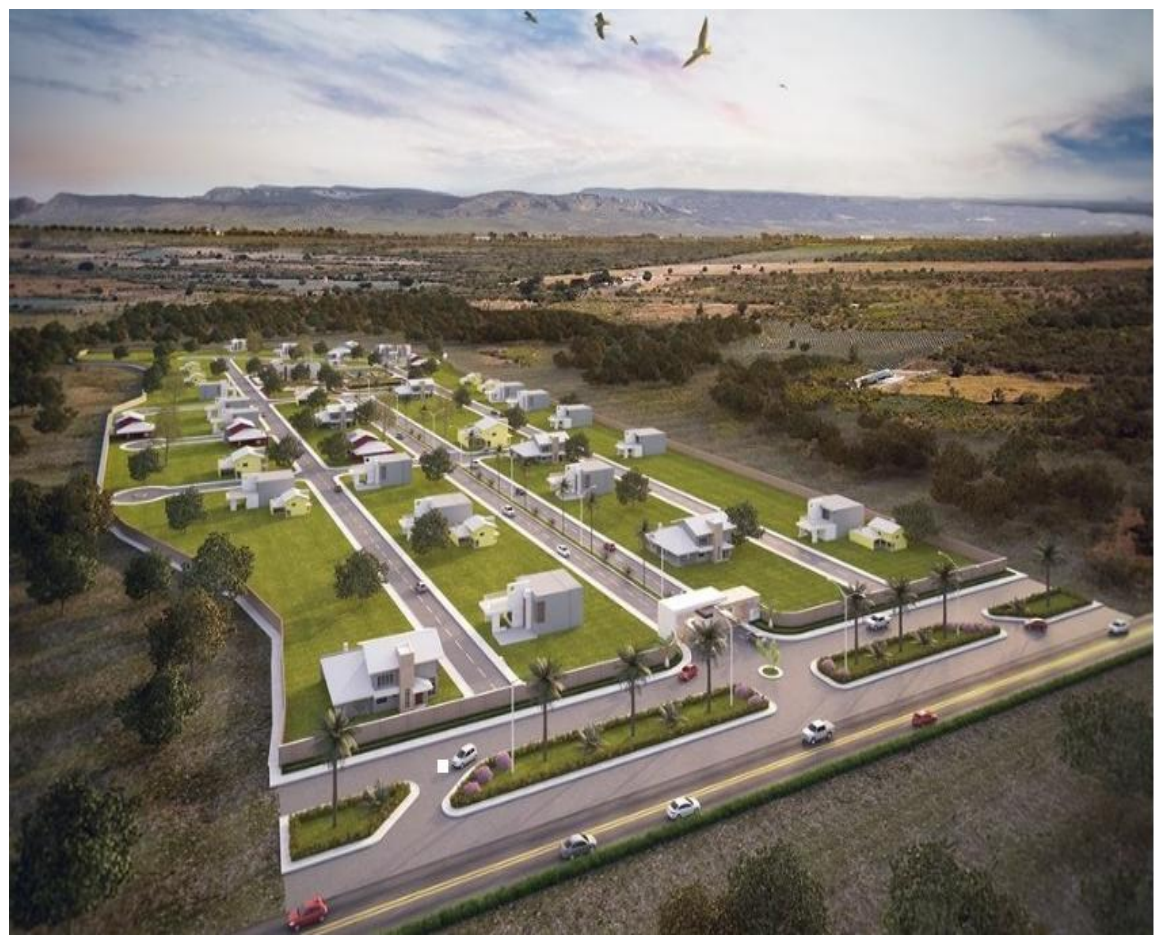

Infraestrutura completa:

- Guarita com segurança 24h, salão de eventos, academia, parque infantil, piscinas, campo de futebol, quiosque, iluminação pública, rede de água potável, pavimentação asfáltica, bosque, paisagismo e áreas verdes.

Venha conhecer as condiç̃ês especiais que preparamos para você e sua família!

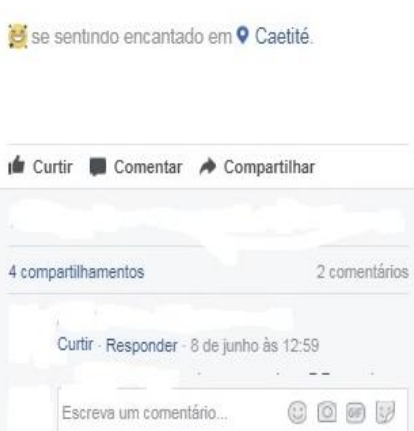

Fonte: Página eletrônica do empreendimento Sindac Imobiliária, 2017.

Assim, as cidades como produto imobiliário constroem atualmente na imagem do condomínio, um conceito de felicidade que se realiza através do consumo e do valor de troca reproduzida na propriedade privada. Uma corrente ideológica e fantasiosa constrói uma cidade feliz e sem conflito esteticamente carregada de fantasia, felicidade e de verde, mesmo 
que apenas simbolicamente, capaz de suprir, por si mesma, as necessidades essenciais aos homens e cumprir papel de satisfação dos desejos criados na contemporaneidade.

Neste caso, observa a propaganda divulgada amplamente nas redes sociais do empreendimento Boulervard das Colinas, na cidade de Caetité-BA, conforme a Imagem 1. O principal objetivo dos incorporadores imobiliários é demonstrar através dos anúncios, o paisagismo bucólico, organizado e repleto de tranquilidade, onde os indivíduos consumidores encontrariam o verde e a felicidade, longe dos transtornos e dos conflitos que movem a cidade contemporânea capitalista.

O fetiche pela imagem coloca nos consumidores um sentimento de felicidade e poder à custa de posições socioeconômicas e diferenciação étnico-racial. Para Harvey (2001)

O fetiche pela imagem coloca num pacote algumas formas estéticas predefinidas, à custa de posições étnicas, justiça social e ambiental, igualdade econômica, racial e social, bem como de questões locais e internacionais de exploração tanto da natureza quanto da natureza humana (HARVEY, 2001, apud HENRIQUE, 2009, p. 105).

Neste sentido, o capital revestido de felicidade e contemplação utiliza-se das propagandas nos diversos empreendimentos imobiliários que escondem a cidade real, criando uma imagem do empreendimento repleta de árvores, bosques, áreas verdes, espaço de lazer, mas que na verdade representa um cenário irreal, pois a maioria dos empreendimentos na sua formação não destroem a natureza, mas sim a transformam e a produz constantemente, na busca incessante pelo lucro e pela valorização das mercadorias e dos objetos.

Partindo desse pressuposto, observa-se que durante a implantação de empreendimentos imobiliários, a forma encontrada pelos produtores é retirada do verde e a transformação do espaço, mesmo aquele já modificado pela ação humana através da agricultura. Desse modo, conforme a Foto 01, observa-se a produção de uma natureza particular e de interesses sob a ótica capitalista imobiliária durante o implantação do empreendimento Boulervard das Colinas, na cidade de Caetité-BA. As árvores, os bosque e as áreas verdes foram suprimidos em detrimento dos interesses capitais.

Sob os interesses capitalistas, o oferecimento de produtos e serviços para as classes com maior poder de consumo, coloca os homens hegemônicos muito próximos da natureza modificada. Uma natureza recriada sob a forma de uma segunda natureza, incorporada, produzida e vendida de acordo com as leis e desejos do modo de produção capitalista. Em busca do lucro os incorporadores se apropriam de locais, dividi-os em lotes retangulares e 
enclausuram os mesmos em muralhas uniformes onde são construídos fortificações e enclaves.

Foto 1 - Construção do Empreendimento Boulervard das Colinas, Caetité - BA, 2017.
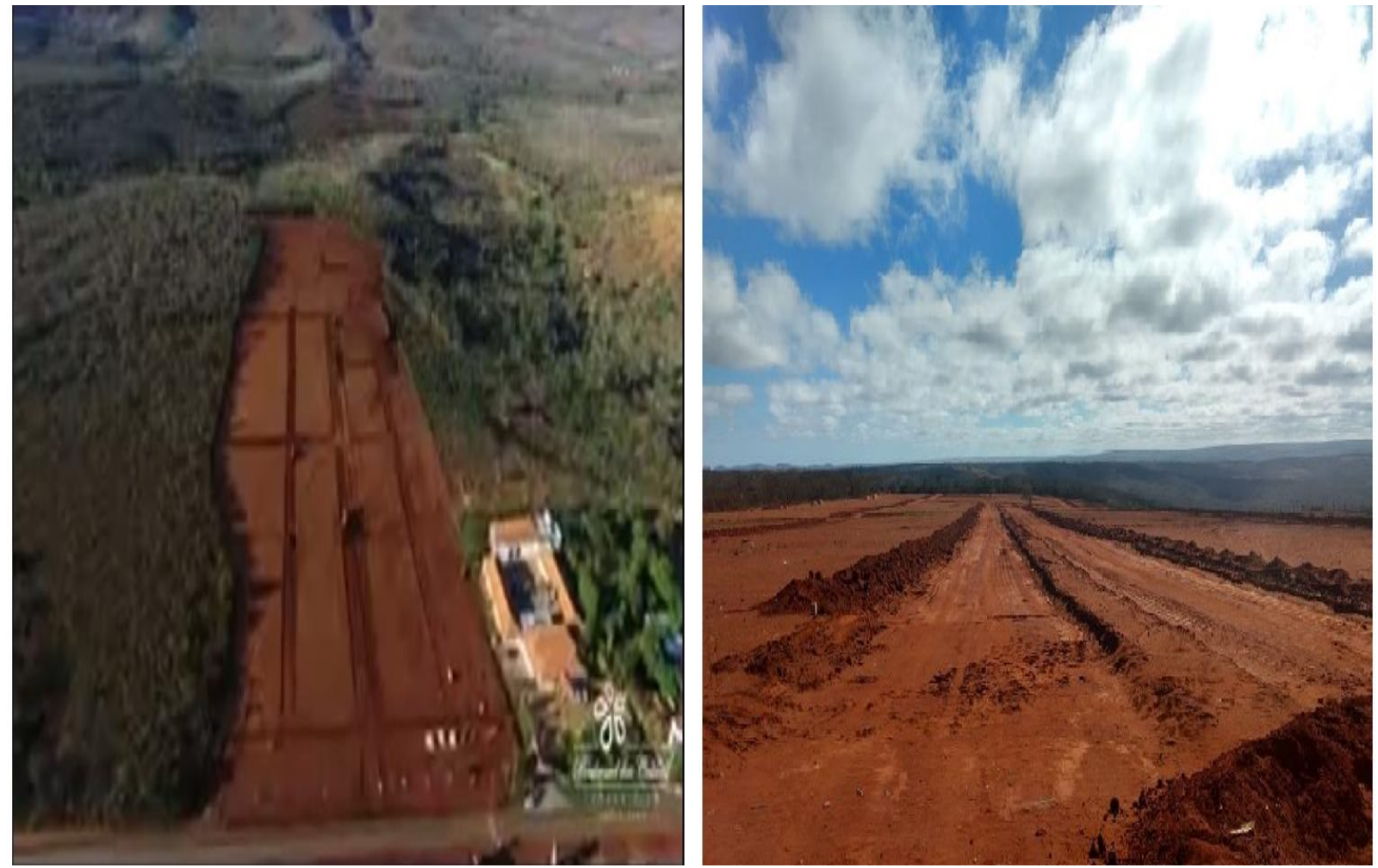

Fonte: Página eletrônica do empreendimento Sindac Imobiliária, 2017.

Cada vez mais a natureza carrega um conteúdo falsificado e comprometido com os interesses capitalistas. Desta forma, a natureza transformada, torna-se uma mercadoria para poucos consumidores, define-se em função do aumento do valor de trocas dos empreendedores imobiliários e a exclusão é exercida a serviço da acumulação.

\section{Do portal que se abre à guarita que se fecha: uma analogia entre o desenho a caverna do dragão e a construção do condomínio boulevard das colinas}

Nos episódios do desenho animado "Caverna do dragão" somos convidados a viajar no universo imaginário, em que emaranhamo-nos em um enredo onde o passado, presente e futuro se conectam. $\mathrm{O}$ desenrolar da história se passa num universo em que personagens como magos, demônios, monstros, mágicas, unicórnios, um mundo real inalcançável e seis jovens, compunham o elenco. Tais jovens se aventuram em um trem fantasma chamado "Caverna do dragão" semelhante a uma montanha russa que, na realidade, é um portal, uma passagem interdimensional, que os levavam para um outro mundo. Assim sendo, para chegarem a esse 
mundo real inalcançável e conseguir um lugar tranquilo, atravessavam um portal e viviam várias aventuras onde a cada episódio era um novo desafio.

É esse mundo inalcançável para a maioria da população que se apresenta o condomínio Boulevard das Colinas. É um "portal” que se abre para a classe abastarda da sociedade e uma guarita que se fecha para a grande maioria da população que não circunda esse espaço. Dessa forma, a classe potencializada da sociedade tem a livre escolha de afastarse da cidade e adentrar em condomínios luxuosos, "seguros", espaço protegido das forças externas.

Partindo do pressuposto da égide de que a desigualdade é inerente ao sistema capitalista, percebe-se um flanco que ratifica o fosso abissal entre as diferentes camadas sociais e seus espaços habitados. Então, a cidade capitalista é lugar ideal para a exposição da lógica da segregação inserida numa conjuntura em que as disparidades socioeconômicas se reforçam e tornam-se mais evidentes. Nesse contexto, "o mundo" dos condomínios fechados é inalcançável por determinados indivíduos que não pertencem à classe que tem condições de atravessar o "portal" e ter acesso ao sonho de consumo disseminado pelo capitalismo.

No desenho, mostrava que o reino era na verdade o Inferno e o Mestre dos Magos, aparentemente, o representante do bem era, também, o demônio - o Vingador, que confundia todos os demais personagens para mantê-los ali condicionados aos seus domínios. Como Mestre dos Magos ou Vingador, "o capital” se apresenta de forma diferente a cada parcela da população. Para a classe hegemônica o capital se apresenta como desfrute, onde todos podem gozar dos bens produzidos e viver num mundo de realizações. Já para os homogeneizados o capital apresenta-se em sua forma mais severa, explorações, fomes, onde o mundo das realizações pessoais se torna inalcançável.

Então, numa perspectiva de análise partindo dos processos de valorização e incorporação da terra, a construção e comercialização do condomínio em estudo traz em si um conteúdo agregado, inerente à natureza da exclusividade da posse e da compra do bem espacial. Dessa forma, como ratifica Ueda (2006, p. 235) "os loteamentos fechados aparecem como uma solução de moradia para os ganhadores, restando aos perdedores a exclusão (o outro lado do muro)". Nesse sentido, as disparidades socioeconômicas contundentes na cidade capitalista, onde se difunde a segregação espacial através dos condomínios verticais e horizontais, o que se propõe implicitamente é um "afastamento simbólico" entre os espaços associado a uma convivência "apartada" por uma muralha que se caracteriza como uma forma de defesa e, também, como status sustentada pelas intenções mercadológicas do capital.

GEOPAUTA, V. 3 no 1, 2019 http://periodicos2.uesb.br/index.php/geo

Este é um artigo de acesso aberto sob a licença Creative Commons da CC BY 
Então, percebe-se que, os seres humanos são mensurados pelo lugar que ocupam no espaço urbano, "o seu valor como produtor, consumidor, cidadão depende da sua localização no território (...) a possibilidade de ser mais ou menos cidadão depende, em larga proporção, do ponto do território onde se está". (SANTOS, 1987, p. 81 apud VERAS, 2001, p.32).

Assim sendo, o grande capital, com a construção dos condomínios fechados, encarrega-se de dotar o espaço de uma infraestrutura eficiente. Então, como aponta Ueda (2006) os condôminos que habitam estes empreendimentos passam por visíveis transformações,

Principalmente, no modo como vivem, consomem, trabalham e gastam seu tempo de lazer. Percebendo essa mudança de comportamento, muitos empreendedores incluíram em seus projetos conjuntos de escritórios e shopping-centers e estão cada vez mais adaptados para terem escolas, hospitais, centros de lazer e parque temático (UEDA, 2006, p. 237)

Dessa forma, marcada pela produção e consumo de bens, a sociedade apresenta suas disparidades sociais "corporificadas" e evidenciadas através da ocupação do espaço. Sobre essa estrutura perversa de segregação socioespacial Ribeiro (1997, p.151) aponta como o capital autorregula a valorização da propriedade e, assim sendo, "para a existência da produção capitalista da moradia foi necessário que, ao longo do tempo, o 'bem moradia' se transformasse no 'bem mercadoria"”.

Neste caso, observa-se a Imagem 02, a guarita do Empreendimento Boulevard das Colinas, que tem como propósito separar indivíduos quanto ao poder de consumo. Para os agentes hegemônicos, ao adentrar na guarita o espaço tem como característica imprimir uma condição de poder, de superioridade possibilitando a classe usufruir da harmonia sociedadenatureza mesmo que construída pelo capital. Para os agentes hegemonizados, a guarita é a negação do sujeito enquanto trabalhador, o acesso ao espaço é negado, para os sujeitos excluídos da prática social dos espaços fechados, existem normas de vigilância na entrada, como na saída. Nesta perspectiva, o propósito é afastar toda a sorte de (in)desejáveis; indesejáveis para a prática socioespacial que se estabelece no espaço, e desejáveis para desempenharem o trabalho braçal (limpeza, manutenção, vigilância, construção civil). 
Imagem 02 - Proposta da Guarita do Empreendimento Boulevard das Colinas.

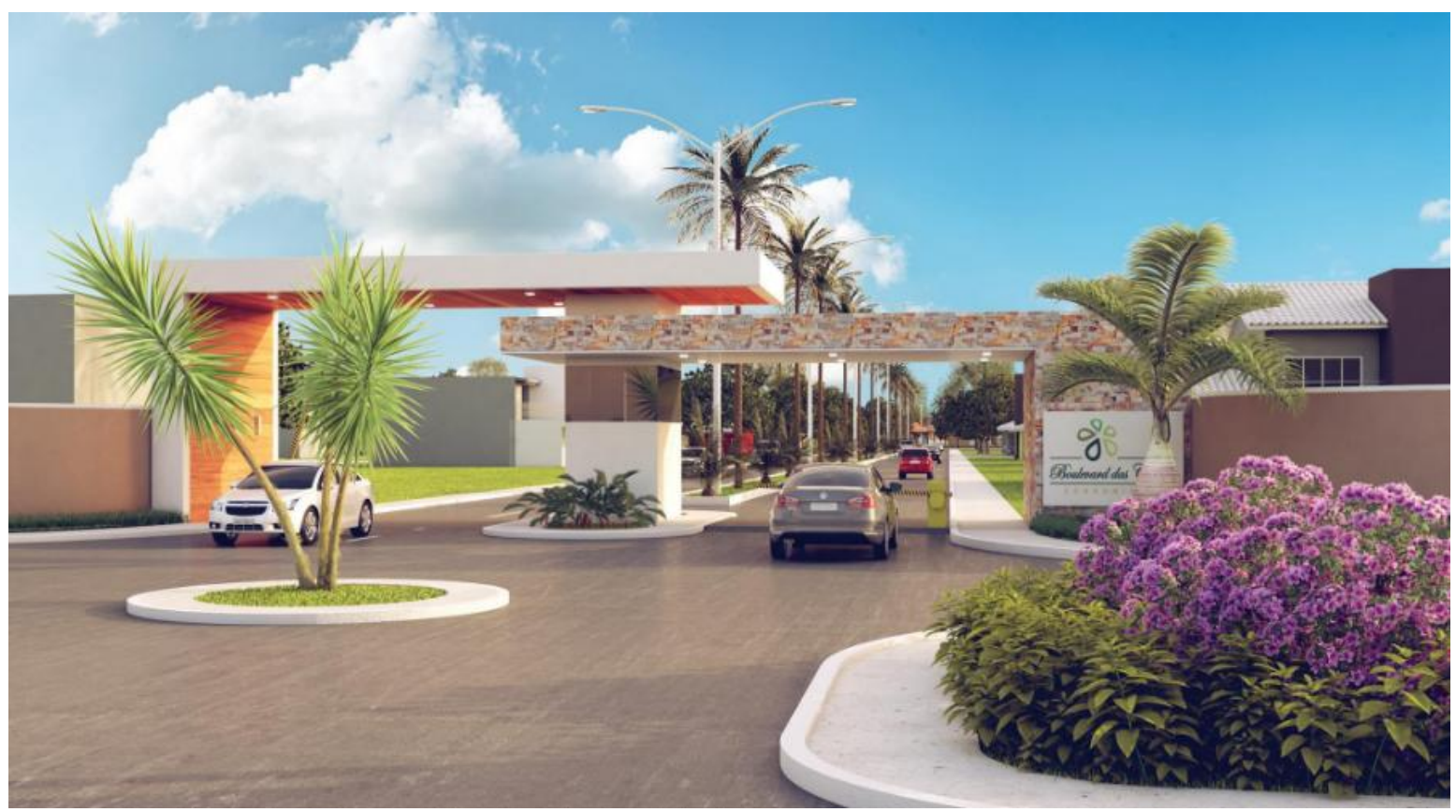

Fonte: Página eletrônica do empreendimento Sindac Imobiliária, 2017.

Destarte, denota-se, então, a apropriação e a produção da natureza têm como objetivo a valorização destes referidos empreendimentos (Condomínio Boulevard), e dessa forma, conjectura-se um simulacro através do codomínio em questão, análogo ao que se apregoa na ideia disseminada ao se adentrar no portal da Caverna do Dragão, um mundo inalcançável dos sonhos, para aqueles que não detêm capital. O capital, então, em sua face devastadora e contraditória abre o "portal" para poucos e fecha a guarita para muitos.

\section{Condomínio boulevaud das colinas: um simulacro e seu possível impacto na cidade de Caetité}

O condomínio Boulevard das Colinas está localizado ao noroeste da cidade de Caetité, na BR 242, que liga o município de Caetité ao município de Igaporã. A presença de espaços residenciais fechados em cidades de diferentes tipos e padrões tem como característica ser um produto imobiliário que busca a maximização de lucros, neste caso, tem como atributo o fechamento e o controle de acesso àqueles que não são seus moradores.

Desta forma, os espaços residenciais fechados permitem a criação de ambientes urbanos de convivência homogênea, na maioria das vezes para indivíduos que possuem a mesma renda, nesta perspectiva, simplificam e negam as experiências na cidade fora dos muros, potencializando e criando um cenário totalmente controlável, longe de quaisquer

GEOPAUTA, V. 3 no 1, 2019 http://periodicos2.uesb.br/index.php/geo

Este é um artigo de acesso aberto sob a licença Creative Commons da CC BY 
ameaças e encontros inesperados. Nestes espaços fechados, a realidade vivida por aqueles que não são moradores é negada, dando espaço para a valorização de uma realidade virtualmente idealizada.

Observa-se que com o aprofundamento dessa tendência e a dinâmica das estruturas urbanas, sob o ponto de vista das práticas socioespaciais, podem levar a instauração de fragmentações socioespaciais. Para Sposito (2013) devemos observar:

Em que medida e de que forma os espaços residenciais fechados têm alterado a distribuição, na cidade, dos grupos sociais e das funções urbanas, rearticulando os usos dos espaços e os fluxos que lhe animam a vida, por meio de formas de segmentação mais complexas, porque incluem o veto ou o controle de acesso e frequência a parcelas do espaço (SPOSITO, 2013, p. 69).

Nesta perspectiva, destaca-se a tendência à localização mais periférica do que central desses empreendimentos, o que é explicável sob o ponto de vista dos proprietários latifundiários e incorporadores. Distantes de área consolidadas e de meios de consumo coletivo (infraestruturas, equipamentos e serviços públicos), os espaços residenciais fechados imprimem novas práticas socioespaciais aos indivíduos que residem nesses espaços. Não diferente dessa tendência observa-se a localização do condomínio Boulevard das Colinas, em Caetité, distante do perímetro urbano e dos equipamentos e serviços públicos, conforme o Mapa 1.

Assim, além de distantes dos centros consolidados os empreendimentos apropriam de áreas antes de produção agrícola e negam a construção social da natureza e todo processo histórico de sua incorporação à vida humana. Confirma-se, neste caso, por exemplo, o condomínio Boulevard das Colinas onde seria possível conviver com a vegetação nativa do sítio onde fora instalado.

Percebe-se nas propagandas e na análise do fato concreto a anulação da cidade e a supervalorização do verde. Observa-se a predominância do verde nos anúncios do empreendimento estudado, as ilustrações das casas, montadas em programas de computador, mostram áreas verdes e a proximidade com o campo, o que não lembram em nada a vista real do local.

Neste perverso mundo de enganação, os incorporadores imobiliários associam cada vez mais, o retorno à natureza. É comum, muitos deles utilizarem da natureza como uma das principais armas para a valorização e exploração capitalista. Neste caso, a relação sociedade-

GEOPAUTA, V. 3 no 1, 2019 http://periodicos2.uesb.br/index.php/geo 
natureza é ideológica, onde os homens não enxergam os fenômenos sociais, políticos ou econômicos que penetram na ideia de natureza. Optam por continuar a ver apenas uma imagem bucólica, que é captada e apropriada pelos empreendimentos imobiliários.

Mapa 1 - Localização do Condomínio Boulevard das Colinas em Caetité

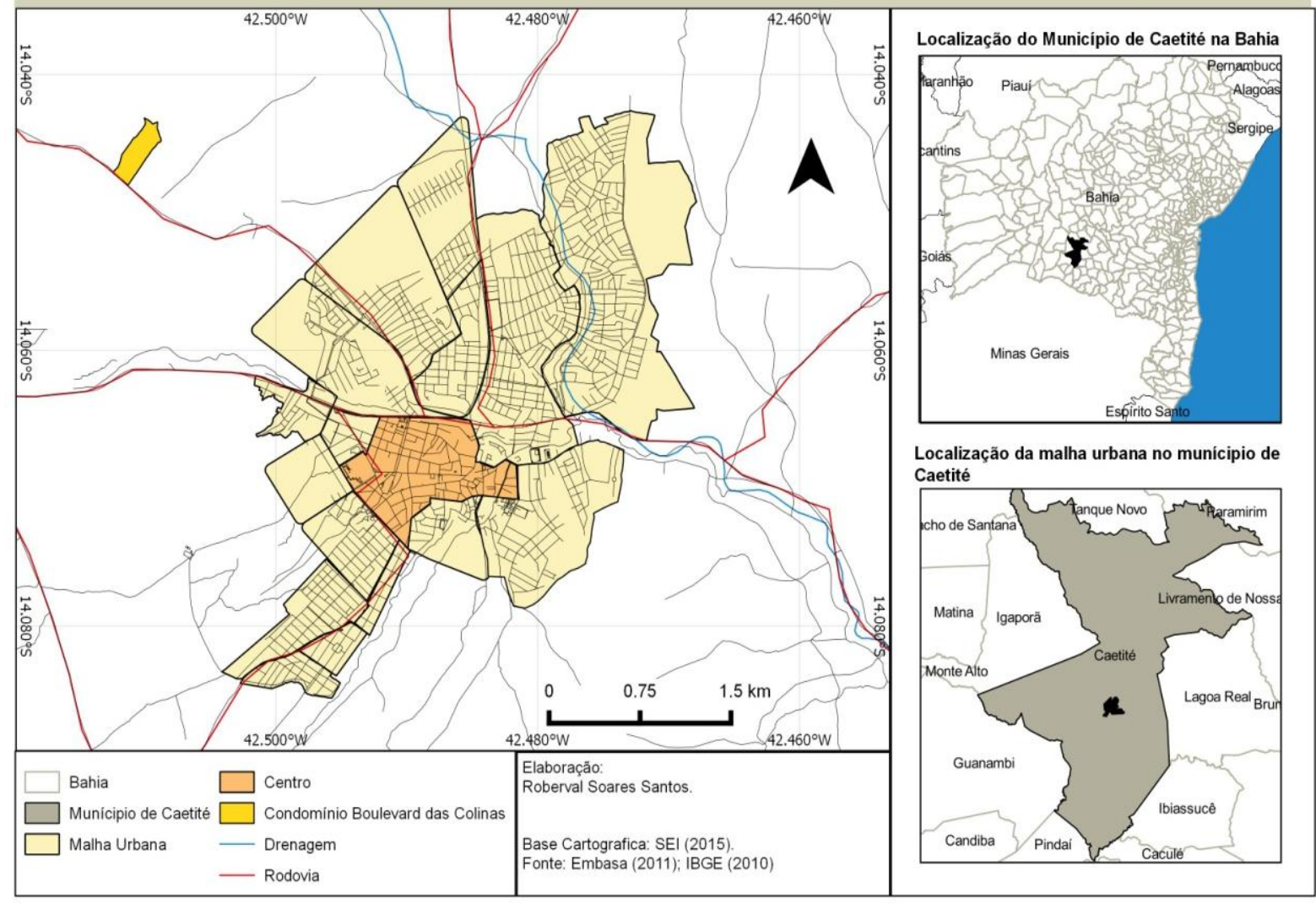

Fonte: Pesquisa, 2017.

Assim um mecanismo para incorporar a ideia de novo e de uma natureza sofisticada, há um novo padrão global de natureza se insere, através da língua. Muitos empreendimentos carregam em seus nomes línguas estrangeiras principalmente: inglês, francês e italiano. Esse método remete ao mundo mais civilizado, sofisticado e elegante, atraindo consumidores de alto padrão que buscam de maneira geral diferenciar-se.

Com isso, os agentes imobiliários constroem e vendem empreendimentos na busca da superexploração do valor de troca, construindo um espaço social, econômico e geograficamente segregado do restante da cidade. Destaca-se, através da análise de propagandas que muitas dessas ideias começam a se materializar no espaço. Desta forma, ato de negar a cidade por eliminação da paisagem, sem integrar a dinâmica urbana, faz com que o condomínio negue também a construção coletiva da natureza, quando ideologicamente 
legitima a satisfação individual de seus moradores ou consumidores em possuir um espaço tão exclusivo.

\section{Considerações finais}

Parte-se da premissa de que a natureza, nesse trabalho, é abordada como mercadoria no espaço urbano em decorrência de ser um produto apropriado por poucos, ou seja, daqueles que podem pagar um preço alto pelos lotes "servidos" pelas amenidades naturais. Essa natureza, representada num mero simulacro, constitui-se num apelo mercadológico com intuito de propagar a venda de lotes nos condomínios fechados.

Sob a égide da propriedade privada e dos distintos interesses, vão se delineando as ações que modificam a natureza numa mercadoria. Nesse sentido, a segregação e a autosegregação socioespacial dissemina-se pela demanda de mercado de reprodução do capital imobiliário que apropria e modifica a natureza, simulacro de um apelo mercadológico potencializador das discrepâncias sociais. Tal segregação tem se manifestado comumente nos condomínios fechados, onde é promovida a estratificação da sociedade, materializados por "enclaves fortificados" com seus muros e guaritas.

Dessa forma, a terra, utilizada para a construção desses condomínios, é considerada um equivalente de capital, através das suas formas de apropriação e uso. No caso do condomínio Boulevard das Colinas, assistimos a um quadro de profundas mudanças que reproduz uma nova espacialidade, mas que não inibe as mazelas impostas por eles, como a segregação socioespacial, a devastação do ambiente, o valor elevado dos lotes, além de impor à sociedade uma estratificação personificada pelos muros e materializada simbolicamente pela natureza.

\section{Referências}

CARLOS, A.F.A. São Paulo: do capital industrial ao capital financeiro. In: CARLOS,Ana Fani A. e OLIVEIRA, Ariovaldo Umbelino (orgs).Geografias de São Paulo, vol 2. São Paulo: Contexto, 2004, pp. 51 a 83

HARVEY, D. A justiça social e a cidade. São Paulo: Hucitec, 1980.

HENRIQUE, W. O Direito à Natureza na Cidade.Salvador: EDUFBA, 2009.

.LEFEBVRE, H. O direito a cidade. São Paulo: Difel, 1969. 
MARX, K. O capital. 6. ed. Rio de Janeiro. Civilização Brasileira, 1980, livro I. Manuscritos econômico-filosóficos. In: FROMM, Erich. Conceito marxista de homem. 2. ed. Rio de Janeiro: Zahar Editores, 1962.

RIBEIRO, L. C. Q. Dos cortiços aos condomínios fechados: as formas de produção da moradia na cidade do Rio de Janeiro. Rio de Janeiro: Civilização Brasileira; IPPUR/UFRJ; FASE, 1997.

SANTOS, D. A reinvenção do espaço. Diálogos em torno da construção do significado de uma categoria. São Paulo, Unesp, 2002.

SILVA, L. R S. A natureza contraditória do espaço geográfico. 2 ed. São Paulo: Contexto, 2001.

SMITH, N. Desenvolvimento desigual. Rio de Janeiro: Editora Bertrand Brasil Ltda, 1988.

SPOSITO, M. E. B; GÓES, E. M. Espaços fechados e cidades: insegurança urbana e fragmentação socioespacial. $1^{a}$ Ed. São Paulo: Editora Unesp, 2013.

UEDA, V. Loteamentos fechados e a produção do espaço urbano: algumas reflexões para o debate. In: SPÓSITO, E. S.; SPÓSITO, M. E. B.; SOBARZO, O. (Orgs.) Cidades Médias: produção do espaço urbano e regional. 1 ed. São Paulo: Editora Expressão Popular, 2006.

VERAS, M. P. B. Exclusão Social: um problema de 500 anos notas preliminares. In: SAWAIA, B (org.). As artimanhas da exclusão: análise psicossocial e ética da desigualdade social. 2 ed. Petrópolis: Editora Vozes, 2001. 